



\title{
Crónica del Seminario A09 "Nuevas y viejas prácticas culturales. Públicos, usuarios y consumidores de la cultura" (XI Seminario del Observatorio Cultural del Proyecto Atalaya). 71 Cursos de Verano de la UCA en Cádiz
}

\author{
Manuel J. Parodi Álvarez \\ Investigador UCA / UAM. Doctor en Historia. Arqueólogo. Analista cultural. Gestor cultural. \\ España. \\ sidiadir@hotmail.com
}

Artículo recibido: 03/02/2021. Revisado: 16/04/2021. Aceptado: 18 /05/2021

\begin{abstract}
Resumen: La $71^{\text {a }}$ edición de los Cursos de Verano de la UCA en Cádiz acogió los días 15 y 16 de julio el seminario "Nuevas y viejas prácticas culturales. Públicos, usuarios y consumidores de la cultura "que siguieron online más de cuarenta profesionales y alumnos y en el que se expusieron los resultados de un estudio sobre los hábitos culturales de los jóvenes universitarios andaluces, realizado por el Observatorio Cultural del Proyecto Atalaya, coordinado por la Universidad de Cádiz y patrocinado por la Consejería de Transformación Económica, Industria, Conocimiento y Universidades de la Junta de Andalucía. El seminario estuvo coordinado por los profesores e investigadores Antonio Javier González Rueda y Jacinto Porro Gutiérrez (Universidad de Cádiz), y Ángel Cazorla Martín (Universidad de Granada) y congregó en su nómina de ponentes a especialistas.
\end{abstract}

Palabras clave: prácticas culturales; gestión cultural; públicos culturales; creadores culturales; usuarios culturales.

Chronicle of the Seminar A09 "New and old cultural practices. Public, users and consumers of culture "

(XI Seminar of the Cultural Observatory of the Atalaya Project). 71 Summer Courses of the UCA in Cádiz.

\begin{abstract}
On July 15 and 16, the 71 st edition of the UCA Summer Courses in Cádiz hosted the seminar "New and old cultural practices. Public, users and consumers of culture "that more than forty professionals and students followed online and in which the results of a study on the cultural habits of young Andalusian university students, carried out by the Cultural Observatory of the Atalaya Project, coordinated by the University of Cádiz and sponsored by the Ministry of Economic Transformation, Industry, Knowledge and Universities of the Junta de Andalucía. The seminar was coordinated by professors and researchers Antonio Javier González Rueda and Jacinto Porro Gutiérrez (University of Cádiz), and Ángel Cazorla Martín (University of Granada) and brought together specialists in its list of speakers.
\end{abstract}

Keywords: cultural practices; cultural management; cultural audiences; cultural creators; cultural users. 


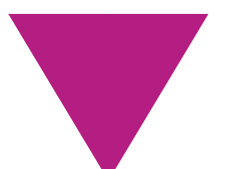

\section{Introducción}

La voluntad y la naturaleza de servicio público de la universidad tiene una de sus formas de expresión acaso más versátiles en el ámbito del análisis social; las universidades públicas andaluzas, desde el Observatorio Cultural del Proyecto Atalaya, vienen desarrollando desde hace años una línea de trabajo sobre el análisis de la cultura, de los usos, prácticas y consumos culturales en la comunidad autónoma -con trascendencia a niveles nacional e internacional- que ha generado un conjunto de 85 estudios sobre la temática señalada.

Una vez editado el producto 85 del Observatorio Cultural del Proyecto Atalaya (OCPA), un trabajo titulado "Las prácticas culturales de los andaluces en el periodo 20062015", el Observatorio, coordinado por la Universidad de Cádiz (UCA) y la Universidad Internacional de Andalucía (UNIA), inició el pasado curso académico (2019-2020) una nueva fase de dicho estudio centrado en las prácticas culturales de los estudiantes universitarios andaluces hasta el año 2020 con un trabajo de campo realizado en plena pandemia del covid19.

468

Partiendo de la encuesta realizada a más de 5000 estudiantes de las diez universidades pú- blicas andaluzas, el estudio "Prácticas culturales de los estudiantes universitarios andaluces", libro redactado por profesores y especialistas de dichas universidades, está a punto de ver la luz. Por ello, y en torno a este trabajo, la $71^{\text {a }}$ edición de los Cursos de Verano de la UCA en Cádiz acogería los días 15 y 16 de julio el seminario "Nuevas y viejas prácticas culturales. Públicos, usuarios y consumidores de la cultura" en el que se expusieron los resultados de este estudio sobre los hábitos culturales de los jóvenes universitarios andaluces además de analizar el consumo cultural en distintos sectores y ámbitos, tanto desde el punto de vista de los creadores y gestores como de las agentes y públicos de la cultura.

El programa formativo de este curso serviría para dar continuidad a la serie de Seminarios del Observatorio Cultural del Proyecto Atalaya con su undécima edición, después de la ausencia del mismo el año 2020 a causa de la pandemia, y se desarrollaría en formato enteramente online con la participación de destacados profesores y especialistas del ámbito universitario y cultural a nivel nacional. El curso se articuló sobre ponencias de formato tradicional pero de media hora de duración, buscando un mayor dinamismo en el desarrollo de la actividad y una mayor potencialidad en las 
interacciones entre ponentes y participantes, que contaban con las herramientas de comunicación virtuales que permite el sistema Zoom para intervenir durante el desarrollo del curso, a lo que fueron animados por los coordinadores, así como sobre diálogos críticos entre pares de ponentes.

Este seminario, celebrado por primera vez en la historia de los cursos estacionales de la UCA íntegramente online, tendría como coordinadores a los profesores e investigadores Antonio J. González Rueda y Jacinto Porro Gutiérrez (Universidad de Cádiz), y Ángel Cazorla Martín (Universidad de Granada), y entre los ponentes del mismo se contaron investigadores de la talla del profesor Manuel Pérez Yruela, un histórico de la sociología en España y pionero del papel de la sociología como herramienta de transformación y mejora de la sociedad, catedrático de Sociología y exdirector del Instituto de Estudios Sociales Avanzados (IESA), quien trató en su ponencia sobre "Cultura y prácticas culturales: el caso de Andalucía".

\section{Esquema técnico del seminario}

Duración: 10 horas

Fecha de celebración: 15 y 16 de julio de 2021.

Lugar/Método de celebración: ONLINE a través de ZOOM (el enlace correspondiente se remitió al alumnado un día antes del comienzo de la actividad).

Convocatoria de Colaboradores/as: https://extension.uca.es/wp-content/uploads/2021/06/ 71CVG.-Convocatoria-de-Colaboradores.pdf

Convocatoria de Becas de Matrícula:

https://app.becas-santander.com/es/program/71-cursosveranouca

Inscripción en:

https://celama.uca.es/71 cursosverano/A09/

\section{Programa}

Coordinadores:

- Ángel Cazorla Martín. Universidad de Granada.

- Antonio Javier González Rueda. Investigador del INDESS (Universidad de Cádiz) y coordinador del Grupo Andaluz de Prácticas Culturales del OCPA.

- Jacinto Porro Gutiérrez. Delegado del Rector para las Políticas de Responsabilidad Social y Corporativa de la Universidad de Cádiz.

\section{5 de julio de 2021}

09.00h. Bienvenida y apertura.

09.15h. Conferencia. "Cultura y prácticas culturales: el caso de Andalucía”. Manuel Pérez Yruela. Catedrático de Sociología y exdirector del Instituto de Estudios Sociales Avanzados (IESA)

09.45 h. Conferencia. "Los Estudios de Prácticas Culturales del Observatorio Cultural del Proyecto Atalaya (OCPA): trayectoria, balance y perspectivas.". Antonio Javier González Rueda. Investigador del INDESS (Universidad de Cádiz) y coordinador del Grupo Andaluz de Prácticas Culturales del OCPA.

10.15h. Pausa.

10.20h. Conferencia. "La música como práctica cultural”. Santi Carrillo. Director de Rockdelux

10.50h. Diálogo. "La música y las prácticas culturales". Noemí Planas. Directora general de Worldwide Independent Network (WIN). Nando Cruz. Periodista cultural.

11.30h. Pausa.

12.00 h. Conferencia. "El cine y el audiovisual como práctica cultural". Eduardo Guillot. Director artístico de la Mostra de València.

12:30h. Diálogo. "Espacios y Prácticas Culturales". Héctor García Barnés. Periodista en "El Confidencial". Daniel Mantero Vázquez. Teniente Alcalde de Cultura del Ayuntamiento de Huelva.

13.10 h. Pausa.

13.15 h. Diálogo. "Medios de comunicación y prácticas culturales." Charo Ramos. Jefa de Cultura de Diario de Sevilla. Óscar López. Director y presentador del programa "Página 2" (RTVE).

13.50 h. Fin de la sesión

\section{6 de julio de 2021}

09.30 h. Conferencia. "Cultura y Universidad: balance de la dimensión cultural". Antonio Ariño Villarroya. Catedrático de Sociología en la Facultat de Ciències Socials y exvicerrector de Cultura e Igualdad de la Universitat de València.

10.00h. Conferencia. "Jóvenes y prácticas culturales: una visión desde Andalucía”. Tristán Pertíñez Blasco. Director gerente del Centro de Estudios Andaluces. Consejería de la Presidencia, Administración Pública e Interior de la Junta de Andalucía. 
10.30 h. Pausa.

10.35 h. Conferencia. "La lectura como práctica cultural". Eva Díaz Pérez. Directora del Centro Andaluz de las Letras de la Consejería de Cultura y Patrimonio Histórico de la Junta de Andalucía.

11.05h. Pausa.

11.35h. Diálogo. "Lectura, autores, patrimonio literario y prácticas culturales". Fernando Zamácola Feijóo. Director Gerente de la Fundación Delibes. Marcelino Sánchez Ruíz. Director de la Fundación Legado Literario Miguel Hernández.

12.15h. Conferencia. "Sociedad digital, ¿nuevas? Tecnologías y prácticas culturales". Paulo Carlos López. Profesor de la Universidad de Santiago de Compostela y coordinador de la ICOMTA'21 - Conferencia Internacional de Comunicación n y Tecnologías Aplicadas.

12.45h. Diálogo. "El género en las prácticas culturales". Cristina Guirao Mirón. Directora del Seminario de Pensamiento y Cultura de la Universidad de Murcia. Fátima Anllo Vento. Directora del Observatorio de Creación Independiente.

13.25 h. Sesión de conclusiones y acto de clausura.

\section{Crónica}

El jueves 15 de julio de 2021 a las 09:00h. tuvo lugar el comienzo del curso (desarrollado en formato online a través de Zoom mediante el enlace https://zoom. us/j/98664290577?pwd=bVRVcGdURWozdEFJcGE4RkszNTIrZz09) con la bienvenida y apertura del mismo que correría a cargo de sus coordinadores, Antonio J. González Rueda (Universidad de Cádiz, investigador del INDESS y coordinador del Grupo Andaluz de Prácticas Culturales del OCPA), Ángel Cazorla Martín (Universidad de Granada) y Jacinto Porro Gutiérrez (delegado del Rector para las Políticas de Responsabilidad Social y Corporativa de la Universidad de Cádiz).

Los coordinadores del Seminario dieron la bienvenida al mismo, señalando que se trata del primer seminario en la historia de la UCA que se imparte íntegramente en modo virtual; A.J. González Rueda señaló el alto nivel de los ponentes y la plena integración de profesionales en entre

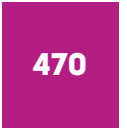
el alumnado del curso, mencionando a los coordinadores del curso, entre los que incluyó a Salvador Catalán, de la UCA; incidió en lo relativo a las ca- racterísticas online del curso y su formato virtual, en lo que atañe especialmente a las cuestiones formales del mismo, tanto en lo temporal como en lo que se refiere a la comunicación; en este sentido señaló que las interacciones del curso se llevasen a cabo mediante el chat, una de las herramientas que ofrece el Zoom, de cara a no lastrar la dinámica del propio seminario.

A.J. González agradeció su presencia a todos los participantes, mencionando al relator del curso, el investigador de la UCA Manuel J. Parodi Álvarez, a quien agradeció especialmente su trabajo durante este seminario, señalando a los asistentes que la relación del curso se publicaría en la revista Periférica.

Á. Cazorla por su parte señaló en su intervención lo novedoso del formato, abundando en la bienvenida a todos los participantes así como mencionando a todos los elementos técnicos y humanos que han hecho posible la organización y desarrollo de este seminario, con especial alusión a dos de los coordinadores del mismo, Salvador Catalán y Antonio Javier González; asimismo hizo mención de la imbricación de este curso en el seno del Observatorio Atalaya, alma mater del proyecto y del curso. Finalizaría felicitando y agradeciendo a todos los participantes, profesorado y alumnado, por su participación en el seminario.

J. Porro comenzó su intervención agradeciendo las palabras de sus compañeros coordinadores del seminario; señalaría cómo cursos como éste ponen de manifiesto el trabajo de todos los intervinientes en el desarrollo y puesta en marcha de los seminarios de los cursos de verano, especialmente de uno como el presente, que cuenta con una perspectiva distinta, con un impacto distinto, especialmente gracias a la propia naturaleza online de los mismos. Señalaría asimismo que el curso es fruto de la línea consolidada de trabajo del grupo de investigación que lo sustenta, así como del Observatorio Atalaya. Cerraría su intervención dando la bienvenida a todos los participantes y cediendo la palabra nuevamente a A.J. González Rueda, quien señalaría también por su parte cómo el Observatorio Atalaya es el sustentador del seminario, agradeciendo asimismo a la Junta de Andalucía y a la Secretaría General de Universidades por su apoyo. Finalmente cedería la palabra a Luis Navarro, sociólogo de la Universidad Pablo de Olavide, quien presentaría a Manuel Pérez Yruela, "santo y seña" de la sociología en España.

Ángel Cazorla presentaría a Antonio Javier González Rueda, cuya conferencia abriría finalmente el seminario (de 
cuya coordinación forma parte) y quien participa en el mismo con su conferencia "Los Estudios de Prácticas Culturales del Observatorio Cultural del Proyecto Atalaya (OCPA): trayectoria, balance y perspectivas". En su presentación, Cazorla incidiría en el carácter intelectualmente inquieto del ponente, así como en su instrucción, en la riqueza que atesora el ponente en lo que se refiere a sus capacidades y herramientas, así como en lo relativo a su enorme capacidad de trabajo, lo que se plasma en su trabajo y sus múltiples responsabilidades en el ámbito de la gestión cultural, haciendo especial mención de su estrecha vinculación con el proyecto Atalaya y su liderazgo desde los comienzos del mismo. Señaló Cazorla que González Rueda presentará los resultados de la última investigación del proyecto Atalaya, desarrollada en momentos especialmente duros como los de la pandemia del covid19; el profesor Cazorla cerró su intervención agradeciendo al ponente su trabajo y su magisterio.

El ponente comenzaría su intervención agradeciendo las palabras de su presentador, tras lo cual proyectaría una intervención de Elvira Sáez González, de la UAL, una "píldora" en la que se comentan algunas de las conclusiones del estudio que sustenta este seminario sobre los usos de los estudiantes universitarios en materia de cultura ("Las prácticas culturales de los andaluces en el periodo 2006-2015”). Tras sendas frases de Sócrates y López Aranguren sobre la consideración (negativa) de la juventud en sus respectivas épocas (de rabiosa contemporaneidad), el ponente expondría una imagen con el equipo humano que ha hecho posible este trabajo, enmarcado en el Observatorio y Proyecto Atalaya (mostrando la red de interacciones y proyecciones del proyecto, como elementos como Flamenco en Red, Contemporarte, Suroscopia o Cacocu, entre otros), con sus distintas iniciativas y líneas de acción. Abundaría en detalle sobre el Observatorio Atalaya y sobre el grupo de prácticas culturales, haciendo un breve histórico (desde 1978) sobre comportamientos culturales y herramientas de análisis de estos comportamientos en España, con elementos como la Encuesta de Hábitos y Prácticas Culturales en España (2002) o el Anuario de estadísticas Culturales del Ministerio de Cultura (2005), haciendo referencia al aparato demoscópico sobre estas cuestiones en el país y señalando cómo la intención del Observatorio, en el que participan todas las universidades públicas andaluzas, era la de trasladar dicha realidad nacional a la escala andaluza.
Entre sus acciones e iniciativas, el grupo ha realizado tres oleadas de análisis de las prácticas culturales de los estudiantes (en 2005, 2012 y 2020), considerando no sólo al grupo de los estudiantes sino atendiendo también a los usos del PDI, del PAS y de la ciudadanía en el entorno de las ciudades con campus universitario, para finalmente estudiar el conjunto de la población andaluza (2013/14), creando un barómetro social con el respaldo de la Junta de Andalucía (2015/16) y realizando un balance de las prácticas culturales en Andalucía (2019). Se trata de un total de diez investigaciones demoscópicas, con más de 30.000 encuestas realizadas, desde 2005 hasta el momento presente, todo ello recurriendo a diferentes vías y cauces de expresión metodológica de dicho trabajo. Dichas 10 investigaciones están disponibles en la web del Observatorio Atalaya, con un enfoque de ciencia abierta y contenidos totalmente accesibles.

En lo que respecta al estudio de 2020 sobre las prácticas culturales de los estudiantes universitarios andaluces señaló que todos los resultados del trabajo están igualmente disponibles en la web. Se han realizado 6803 entrevistas web, con 3600 entrevistas ajustadas al muestreo; el ponente expuso las características técnicas del estudio, señalando la relevancia de que se ha realizado con encuestas mediante la red, algo que supone un cambio esencial en lo que toca a las posibilidades del análisis en general. Señaló González las características de los usos de internet por parte de los universitarios: en ese sentido, por ejemplo, puso de manifiesto que los usos de internet ponen de manifiesto que el día tiene 24 horas, esto es, que los nuevos usos de internet hacen que las 24 horas sean horas disponibles para los consumos de internet de los usuarios, lo que no deja al margen a los consumos culturales por parte de esos usuarios; ello pone de manifiesto una realidad diferente, si no disruptiva, con respecto a las (ya) viejas prácticas culturales no directamente relacionadas con los nuevos modos impuestos por internet.

Expuso el ponente las áreas de mayor interés para los usuarios, como la música, el cine, la lectura, la práctica de actividad cultural las artes escénicas, la TV, los videojuegos y la radio (señalados en orden descendente), apuntando igualmente cómo han cambiado las referencias de los hábitos y demandas culturales de los universitarios en estos años de desarrollo del trabajo del Observatorio y el Proyecto Atalaya. Como botón de muestra expondría el ponente un artículo de 2009 cuyos 
contenidos han venido a quedar pronto desfasados a causa de la propia movilidad de los usos y prácticas de los usuarios de internet desde ese año 2009 hasta hoy, 2021.

A modo de conclusiones el ponente señaló cuestiones como que la conexión a internet es generalizada, el móvil es la herramienta más utilizada, no hay patrones comunes en el consumo de cine, prensa, música, radio, el cine se consume mayoritariamente online; en la mayor parte de los hogares de los universitarios andaluces ha irrumpido la TV de pago. No se han detectado factores territoriales o geográficos en las prácticas temporales; ni el 2009 ni ahora los universitarios dejan de ser ciudadanos globalizados: no conforman élites, como tampoco lo hacen los miembros del PDI o del PAS; ello debe hacer reconsiderar el "lugar común" de las inteligencias y las élites universitarias; las ciudades con campus no tienen uso diferentes de aquellas que no cuentan con campus, y la universidad no es un agente sustancial de cambio en los usos culturales de su entorno.

Para concluir, el ponente planteó las líneas (posibles) de acción en el futuro, no negando los indicios de cansancio en el grupo y señalando la necesidad de regresar a los usos cuantitativos y al trato más directo en la acción. Al cierre de la conferencia del profesor González Rueda su presentador, Ángel Cazorla, agradeció su intervención cediendo la palabra al profesor Luis Navarro, presentador a su vez del profesor Manuel Pérez Yruela.

Luis Navarro Ardoy agradecería su intervención a A.J. González Rueda, presentando acto seguido al profesor Pérez Yruela y haciendo la glosa de su trayectoria profesional como sociólogo; en este sentido L. Navarro señalaría que su trayectoria profesional ha marcado un antes y un después en el desarrollo de la sociología en nuestro país. Hizo hincapié en la convicción del profesor Pérez Yruela del papel de la sociología como herramienta de transformación y mejora de la sociedad, y como constructor de la disciplina en Andalucía a través del Instituto de Estudios Sociales Avanzados (IESA). Su capacidad de análisis, señaló el presentador, ha ayudado a desarrollar el estudio del presente para comprender los porqués de dónde estamos y de hacia dónde podemos ir como sociedad.

Finalmente a las 10:00 h. daría comienzo

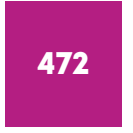
la conferencia "Cultura y prácticas culturales: el caso de Andalucía”, a cargo del profesor Manuel Pérez Yruela, catedrático de Sociología y exdirec- tor del Instituto de Estudios Sociales Avanzados (IESA), tras la presentación de su figura por el profesor Navarro Ardoy. El profesor Pérez Yruela inició su ponencia haciendo referencia a las pautas de acceso a la cultura en Andalucía desde una perspectiva histórica en la región, señalando dos elementos clave: nuestra dependencia respecto al pasado, de una parte, y la modernización producida en los últimos 40 años en Andalucía, con el profundo cambio generacional sucedido en la región en este último casi medio siglo.

Planteó el ponente la cuestión de qué entienden los andaluces por cultura, lo que tiene que ver con las propias raíces identitarias de la región y su gente, algo que no se puede disociar con el antedicho rápido proceso de cambio de la comunidad en los últimos 40 años, un proceso que el conferenciante considera lastrado por cuestiones como la falta de formación y la escasez de recursos (pese a los picos de fines de los 90 y comienzos de los 2000); así, Pérez Yruela señaló la necesidad de formular una nueva teoría de Andalucía.

El ponente señaló la relación por él establecida entre las prácticas culturales de los andaluces, los niveles de renta de los mismos y su nivel de formación, expresando diversas cuestiones cuantitativas sobre este particular: la cultura en Andalucía está fuertemente vinculada con el nivel socioeconómico de los ciudadanos, más aún que con su nivel educativo; en este sentido, el ponente expuso cifras sobre los niveles de formación en distintas regiones españoles, incluida Andalucía, y en el conjunto del país, señalando cómo Andalucía sigue estando peor posicionada que el resto del país en lo que a los niveles de formación se refiere, lo que Pérez Yruela puso en relación con el lastre de la situación tradicional y con la existencia de dos Andalucías en lo que a la formación se refiere: una aún lastrada por el mal o escaso acceso a la formación y otra que goza de un buen nivel educativo. Todo ello fue puesto en relación por el conferenciante con cuestiones de naturaleza demográfica y geográfica, señalando factores de asentamiento de la población como elementos clave a la hora de explicar el acceso o no a los bienes culturales y al consumo cultural por parte de la población andaluza: la accesibilidad a la cultura también tiene que ver con las posibilidades de acceso físico a la misma, al menos en la perspectiva tradicional de los usos culturales no relacionados con internet, y ello sin olvidar las cuestiones relacionadas con los niveles de renta (la renta media de Andalucía era del 78'4\% de la media nacional en 2019 y 84\% en 2008, según expon- 
dría el ponente): casi un tercio de la población andaluza se encuentra bajo los umbrales del riesgo de pobreza, lo que hace que todavía los andaluces, lastrados aún por la herencia del pasado, no tengan un fácil acceso a la cultura. Especialmente vista desde fuera, señala el conferenciante, la sociedad andaluza presenta un gran peso de la cultura tradicional y en buena medida anclada en tópicos, frente a un menos peso de la cultura moderna, de la cultura creativa y de la cultura innovadora.

Entrando en la segunda parte de su intervención, el conferenciante abordaría líneas de acción del IESA, como cuestiones relativas a los equipamientos culturales de Andalucía, con porcentajes comparativos entre España y Andalucía en diferentes aspectos de lo señalado, como el uso de TV e internet, la presencia de libros en papel en los hogares, o el uso de dispositivos como ordenadores, libros digitales o tablets.

En lo que respecta a la propia opinión de los andaluces sobre su nivel cultural, nos consideramos menos cultos que el resto de los españoles o de los europeos, siendo que sin embargo los andaluces de hoy se consideran mejor formados que sus padres. Respecto a los hábitos culturales de los andaluces, apuntaría que siguen existiendo pequeñas diferencias respecto al conjunto de España, como en la mejor lectura de periódicos o el interés, también menor, por las bibliotecas o las artes escénicas, mientras algo diferente sucede con la música o el cine, donde la tendencia se invierte entre España y Andalucía.

En lo relativo al significado de la cultura para los andaluces, la cultura es sobre todo formación y conocimiento(s), lo que el ponente pone en relación con el que la formación haya servido como ascensor social en Andalucía a lo largo del tiempo; muy vinculado a ello, están valoraciones como el valor de la cultura como herramienta para el disfrute o para la capacidad de comprensión de lo que sucede, de la realidad y las noticias, del mundo que nos rodea en fin de cuentas.

Como conclusiones, el ponente señaló que la cultura evoca a los andaluces cuestiones como las Letras, la Ciencia, las Bellas Artes, los viajes y el deporte, pero este mundo de valores que evoca la palabra cultura a los andaluces es un horizonte en vías de cambio, donde sin embargo los valores tradicionales siguen siendo referentes a considerar. La cultura sigue siendo fundamentalmente conocimiento en el imaginario de los andaluces; el Flamenco tiene una elevada consideración como elemento cultural; nuestro acceso a la cultura sigue limitado por la condición socioeconómica de los andaluces y por la herencia del pasado; nuestra percepción de la cultura sigue estando muy ligada a su papel como ascensor social.

Con estas consideraciones y su agradecimiento a la organización, el profesor Pérez Yruela cerraría su intervención, tras lo cual su presentador retomó la palabra para ponderar la ponencia y recordar consideraciones precedentes del conferenciante, cediendo a su vez la palabra a A.J. González Rueda, quien por su parte daría paso a la siguiente intervención, la conferencia "La música como práctica cultural", a cargo de Santi Carrillo, director de Rockdelux desde 1987.

A las $10.30 \mathrm{~h}$. comenzaría la referida conferencia titulada "La música como práctica cultural", a cargo de Santi Carrillo quien sería presentado por Salvador Catalán Romero, director de actividades culturales del Servicio de Extensión Cultural de la UCA (definido a su vez por los coordinadores del curso como el cuarto coordinador del seminario), precedida de otra "píldora" del proyecto, a cargo de Gema María Marín Carrillo, de la UAL.

Salvador Catalán haría la glosa del ponente señalando su profunda relación con la música y la difusión cultural en el ámbito musical desde hace décadas, así como sus vinculaciones con el mundo universitario, tras lo que cedió la palabra a Carrillo, quien comenzaría su intervención realizando un breve histórico sobre Rockdelux desde sus inicios a mediados de los 80 como referencia en la prensa músical en lengua castellana dentro y fuera de España así como sobre sus conexiones globales con el mundo de la música merced a su trayectoria y a su naturaleza digital desde 2020, conectando con nuevos públicos que se suman a los públicos tradicionales de la revista.

La música, según el ponente, nunca se va a detener, ligada como está a la Historia de la Humanidad; creadora y exponente de modas y tendencias, la música ayuda a definir socialmente a la Humanidad mejor que otras manifestaciones culturales, de acuerdo con el conferenciante, que señalaría que la revista trata siempre de atender a las líneas musicales de cada momento partiendo de una base heterogénea y plural que procura atender a gustos mayoritarios y minoritarios, desde un criterio ya contrastado a lo largo de los años y sin temor a abordar lo que algunos llaman "cosas raras", que sin embargo la 
revista no renuncia a considerar junto a cuestiones más comerciales, pues se intenta que se priorice el criterio artístico sobre otros considerandos.

Carrillo señaló (coincidiendo con ponentes precedentes) que, en lo que se refiere a las herramientas técnicas de los consumos culturales, el teléfono es la principal de las mismas, lo que lleva a adaptar los contenidos culturales a los formatos disponibles en el móvil; igualmente apuntó la incidencia de internet en lo que se refiere a los horarios de consumo cultural; en ese sentido manifestó que internet viene a ser una infinita biblioteca virtual disponible las 24 horas del día, lo que hace que el tiempo de consumo cultural en modo tradicional no pare de decrecer, exponiendo diversas cuestiones cuantitativas relativas a los consumos culturales en España en relación con la incidencia de la realidad virtual y la cultura online.

En lo que toca a la música, señaló que sólo un 1\% de los encuestados en el proyecto que se analiza en el curso reconoce no escuchar música nunca frente a un $80 \%$ de los encuestados que señalan que la música forma parte de su horizonte habitual; en lo que atañe al rock, señaló que es música de referencia en el sector femenino, frente a un segmento masculino más cercano a las nuevas músicas urbanas. Igualmente se detuvo a considerar el mayor impacto de los consumos culturales en personas de un mayor nivel socioeconómico: en dicho sentido, señaló que los lectores de Rockdelux son mayoritariamente personas de formación universitaria y de un mayor nivel de renta.

Señaló el ponente cómo la realidad cultural de los más jóvenes esta' "mediatizada por las pantallas", con la "hegemonía de los influencers", algo totalmente nuevo y que rompe las pautas de comportamiento anterior, frente a lo cual Carrillo apuntó la necesidad de romper todo tipo de barreras "tutelares", siendo que la cultura es siempre un elemento vehiculador de los comportamientos sociales, señalando asimismo el papel de la cultura escrita como agente transformador y transmisor de conocimiento y, por ello, como elemento a la vez de continuidad cultural y de ruptura. La cultura escrita, señaló, ya se trate de material físico o mediante soporte digital, debe mantenerse de cara al futuro, pues permitirá enriquecer a las generaciones posibles, combinándose para ello los mecanismos tradicionales con las nuevas tecnologías en lo que atañe a los consumos culturales.
Todo ello, además, es puesto en relación por el ponente con la construcción y existencia de valores incluso políticos en el seno de las sociedades, algo que pone en relación con los modos de consumo cultural por parte de los universitarios andaluces en función de su propia adscripción e identificación ideológica; al mismo tiempo Santi Carrillo incidiría en cómo muy pocos consumidores culturales señalan asistir en vivo a espectáculos musicales, frente a lo que sucede con los consumos musicales vía digital.

El conferenciante, en fin, hizo hincapié en la necesidad de la valoración económica de la cultura y del consumo cultural (lo que nos lleva a la cuestión esencial de la economía de la cultura), señalando lo pernicioso de la gratuidad de la cultura en general y del consumo cultural en internet en particular: específicamente señaló que internet no puede ser eternamente gratis, porque ello lleva a que "la gente no pueda vivir de su trabajo", lo que repercutirá negativamente en la calidad de los contenidos y aun de la propia creación de contenidos culturales, lo que el ponente puso en relación con la pérdida de calidad progresiva en los contenidos culturales que se crean en la actualidad.

Para cerrar su intervención, el ponente incidió en sus últimas líneas argumentales sobre lo pernicioso de la gratuidad en materia de consumos culturales especialmente en el horizonte digital.

$\mathrm{Al}$ cabo de esta ponencia retomó la palabra Salvador Catalán Romero para ponderar las líneas de la misma y ponerla en conexión con futuras sesiones de este seminario y presentar la siguiente píldora del estudio, a cargo de Luis M. Medina, de la UCO, tras la cual anunciaría se desarrollaría el diálogo "La música y las prácticas culturales", entre Noemí Planas, directora general de Worldwide Independent Network (WIN), y Nando Cruz, periodista cultural, que serían presentados por el mismo S. Catalán, que daría comienzo a las 11:05 de la mañana.

Tomaría la palabra Noemí Planas, quien agradeció la invitación a participar en el seminario para a continuación desarrollar una presentación de su trabajo y sobre los consumos musicales especialmente en el contexto de la pandemia, centrándose especialmente en la música grabada. De acuerdo con la Encuesta de consumos y hábitos culturales en España, la actividad cultural más común y extendida es el consumo de música, especialmente de la grabada, sin grandes diferencias por sexos o edades. 
Intervino a continuación Nando Cruz, quien señaló que se centraría más en la música en vivo, una industria muy musculada y poderosa en estos últimos años de acuerdo con lo expuesto por el ponente, que se vertebra en un tejido que involucra grandes valores humanos y de mercado, siendo un negocio cada vez más concentrado en pocas manos; se produce una doble concentración, de negocio y de acción, con grandes festivales concentrados en cortos espacios de tiempo, los macrofestivales. Este proceso, el de los macrofestivales, se ha acentuado en los últimos años según N. Cruz, quien señala asimismo que en el momento actual, y gracias a la música grabada, la música es omnipresente en nuestras vidas, mientras la música en vivo es una suerte de "guinda" del pastel musical, una guinda a la que no todo el mundo quiere acceder, frente a lo que sucede con la música grabada; ello tiene que ver con el "formato atracón" (sic) de los grandes macrofestivales, donde se ofrece "todo lo que hay que oír" en un año determinado, un formato en el que se consume de forma concentrada una oferta que en realidad es enorme, siendo que el "atracón" se ha convertido en un modelo de consumo en la actualidad, y ello a muchos niveles (series, música, TV ...), de acuerdo con el ponente, quien señala que estamos en un momento clave enlo que atañe al consumo musical, un momento digno de análisis y estudio.

Salvador Catalán, moderador del diálogo, señalaría que hay una diferencia entre la asistencia a festivales y la asistencia al modelo de circuitos, siendo que el modelo de macrofestivales incide negativamente en la propia existencia de los circuitos, que se debilitan ante la extraordinaria presión de los festivales; Nando Cruz, a este respecto, señalaría que al principio el discurso era el de la retroalimentación: los festivales servirían para alimentar a los circuitos, frente a lo que realmente sucede: a muchos grupos se les plantean cuestiones de exclusividad a la hora de participar en festivales que indicen negativamente en los circuitos, al mermar su posible presencia en el país tras (y ante) su presencia en macrofestivales.

Noemí Planas señalaría por su parte, abundando en esta línea argumental, que la pérdida del circuito de salas incide además negativamente en el desarrollo del tejido emergente en los grupos musicales, lo que puede desertizar, señalaría Cruz, el consumo de músicas en vivo por parte de grupos incipientes, emergentes, que optan por grabar y por entrar en macrofestivales, frente a su participación en cir- cuitos de sala, considerado en todo caso como una opción secundaria frente a la opción de los grandes festivales para estos grupos emergentes, lo que en cualquier caso repercute negativamente en la creación musical y los consumos musicales en España.

A.J. González intervendría para plantear si incluso el formato de música en vivo no podría convertirse, en breve, en una "vieja práctica"; N. Planas respondería que si bien el directo tiene ese carisma de siempre, los nuevos hábitos de consumo cultural y la existencia del mundo virtual pueden plantear la paulatina desaparición de modelos y hábitos especialmente en una población joven que nace como "nativa digital" y que pueda tener consideraciones y necesidades diferentes respecto a los públicos actuales. Nando Cruz, por su parte, señalaría que los festivales a su vez se están encontrando con un progresivo envejecimiento de sus públicos: los públicos más jóvenes crecen con otras propuestas que les llevan a valorar cuestiones distintas de las tradicionales, que pueden llevar a los consumos musicales en vivo a un gran cambio en breve, con un público joven cada vez más inmerso en los consumos digitales frente al mundo "real", tangible, analógico.

N. Planas por su parte expondría varios ejemplos de elementos de cambio en los consumos musicales a lo largo de la historia reciente, desde la perspectiva de lo tecnológico, por ejemplo, con herramientas, como el fonógrafo, que llevarían a cambios en los consumos musicales a partir de su irrupción en el mercado, con la aparición por ejemplo de la música grabada, contribuyendo por ejemplo a la difusión de músicas como el jazz o la música clásica, que salen de espacios reservados (sociales, étnicos, geográficos) gracias a la música grabada.

En lo que toca al mercado de música grabada, Planas abundaría en el polimorfismo de los espacios de la misma, planteando la evolución del mercado de ventas de música grabada en los últimos 20 años, con la incidencia en el mismo de la realidad digital. Como singularidad, la ponente planteó el resurgir del formato en vinilo, desahuciado en su día y recuperado sorprendentemente con posterioridad; al mismo tiempo señaló cómo la música ha dejado de ser un bien para convertirse en un servicio que se usa, en la década de los 2000, frente a lo cual se produciría una reacción que la ponente puso en relación (esta idea de la posesión de lo tangible) con el resurgimiento del vinilo. 
Salvador Catalán, con ánimo de cerrar el diálogo, expuso que este cambio de paradigma vivido en los últimos tiempos (de la música grabada al streaming), y preguntó a los ponentes si consideraban que este cambio ha llegado para quedarse, si esta relación consumidor-streaming sería tan larga y exitosa como en el caso de formatos anteriores. Noemí Planas en su respuesta señalaría que las nuevas fórmulas han llegado para quedarse, y que lo que pueden cambiar serán las plataformas y los considerandos técnicos, entrando en un discurso de energía y de sostenibilidad mucho más amplio.

Nando Cruz, para concluir, puntualizó en lo tocante a los consumos en vivo que existen muchos modos de música en vivo en contextos urbanos de distintos tamaños, modelos no asumidos como la industria sumergida de música en vivo, apuntando que en realidad, sumada toda esta realidad no cuantificable o difícilmente cuantificable, supera al volumen de personas que asisten a macrofestivales; en este sentido, pues, los otros modelos de consumo de música en vivo superan a la gran industria musical de los macrofestivales, algo que se desconoce o incluso no se difunde, se oculta de un modo u otro, se invisibiliza y no trasciende.

N. Planas, finalmente, hablaría de la remuneración a los artistas, de la realidad económica de un tejido creativo que no ha podido nutrirse del aspecto en vivo de su trabajo; en este sentido señaló que ningún artista "medianito" (sic) en España puede vivir exclusivamente del streaming; apuntó la necesidad de regulación de la realidad digital por parte de la administración, con la directiva europea de derechos de autor de 2019 que el gobierno de España aún no ha implementado en el país, lo que deja en situación de desamparo a los creadores y artistas; la ponente aludió asimismo a la responsabilidad de los consumidores a la hora de orientar su consumo en el mundo digital, porque ello tendrá diferente repercusión -económica- en los creadores y los intérpretes.

Salvador Catalán cerraría el diálogo entre Nando Cruz y Noemí Planas agradeciendo a ambos su intervención en este seminario, tras lo cual Antonio J. Rueda hizo una breve comparativa entre los mundos musical y literario a la hora de la responsabilidad del consumo cultural, en lo que abundaría asimismo brevemente Nando Cruz, en la línea de lo expuesto por su compañera de diálogo.

Tras la pausa prevista, se retomó el desarrollo del seminario a las 12:10h. con la conferencia titulada "El cine y el audiovisual como práctica cultural", a cargo de Eduardo Guillot, director artístico de la Mostra de València, tras la correspondiente píldora del estudio del Observatorio sobre usos culturales de los universitarios andaluces, a cargo de Fátima Recuero López, de la UGR.

Jacinto Porro presentaría la conferencia de Eduardo Guillot, poniendo sobre la mesa los valores del cine como transmisor de sentimientos y valores, como ventana a los sueños y a la vez como producto social y cultural, que nos conecta con la vida propia y la ajena, de todo lo cual viene a hablar Eduardo Guillot, cuya trayectoria profesional, fuertemente vinculada con la cinematografía y la música, así como con la literatura y la cultura rock, glosaría el profesor Porro en su intervención.

Eduardo Guillot comenzaría su intervención agradeciendo la invitación a participar en este seminario, haciendo especial mención a Rockdelux, Santi Carrillo, Nando Cruz y Noemí Planas, con quien tiene especiales conexiones profesionales por su propia trayectoria.

Señaló que lo dilatado de su trayectoria le ofrece quizá especiales herramientas para la consideración de cuestiones tales como que hablar de "práctica cultural" es hablar siempre de "industria cultural", poniendo de manifiesto el aspecto económico de la cultura y el papel económico de la cultura como elemento inherente de su propia naturaleza, lo que se hace especialmente evidente en el ámbito del cine: las películas, señala, tiene un proceso económico largo y no siempre sencillo de producción, y existe un fenómeno de invisibilidad para muchas películas que no trascienden suficientemente; ello contribuye a que exista una fuerte conexión entre el éxito comercial de las películas y los festivales, que a veces son la plataforma para el conocimiento de un producto cinematográfico dado.

A veces, señala el ponente, el arte "queda a un lado" frente al peso económico del sistema, quedando a veces las películas fuera del control de sus propios creadores: la obra en un momento determinado deja de pertenecer al autor de la obra debido a la intervención de los muchos elementos que forman el paisaje del panorama cinematográfico.

El ponente señaló que el enfoque de su intervención aunaría lo personal con lo profesional, en un contexto que no vaciló en reconocer como lleno de dudas e incertezas. Hizo el distingo entre cine y audiovisual, que engloba muchos más perfiles y que incluye, por ejemplo, a la televisión con to- 


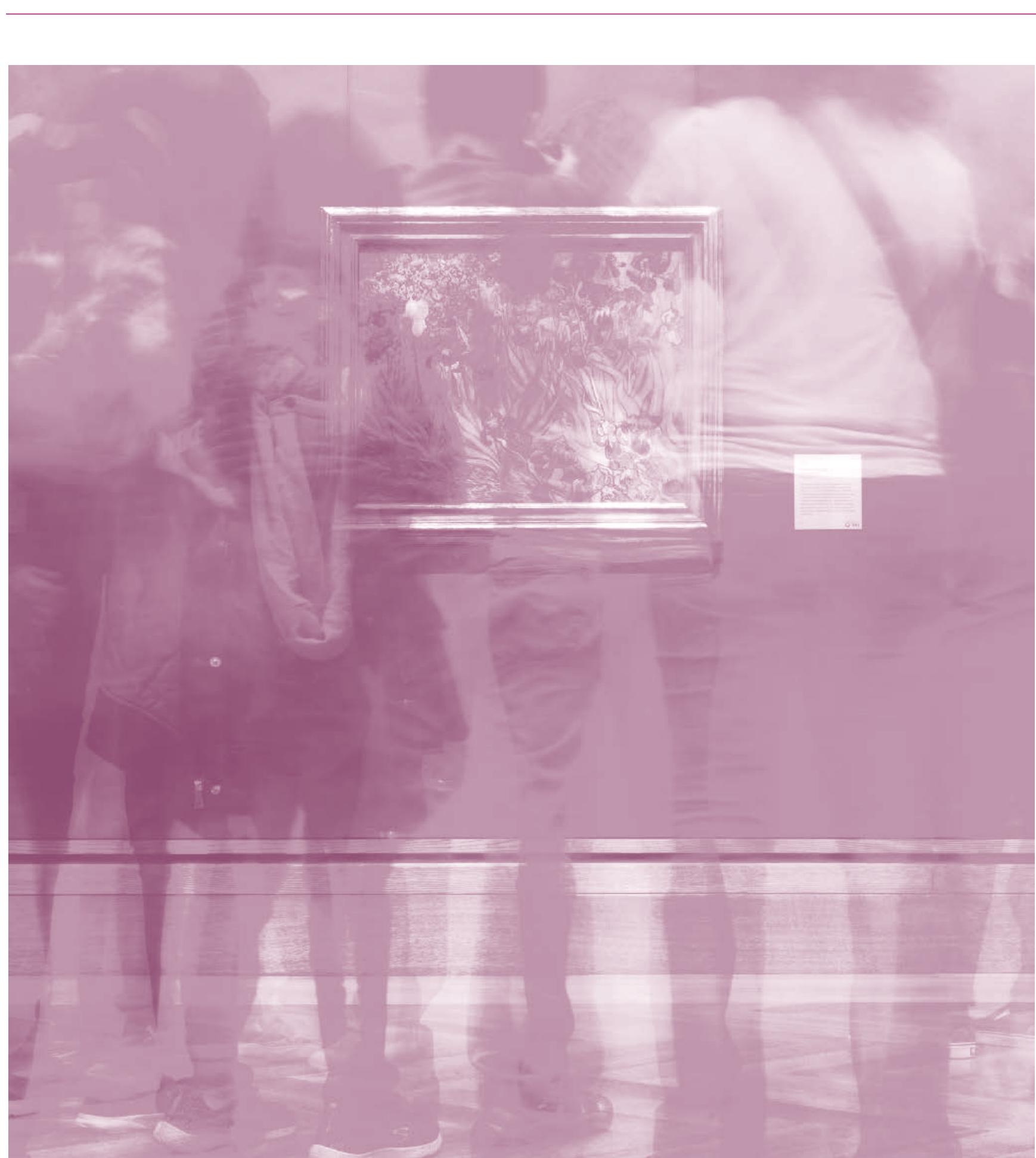


dos sus distintos formatos, y señaló que no podemos hablar de "audiovisual" refiriéndonos solamente al mundo del cine (acaso la rama privilegiada de ese espectro "audiovisual"), apoyándose por ejemplo en los distintos presupuestos que se manejan en el mundo de la publicidad o en el mundo del cine, especialmente desde la irrupción del mundo digital, con las plataformas y el streaming.

Planteó el ponente cuestiones como el papel de la crítica de cine o el acceso gratuito a los contenidos en el mundo digital, que ha llevado progresivamente a los espectadores a prescindir de la prescripción de la crítica: al estar la película en plataformas al mismo tiempo que la ven los periodistas, esa labor de prescripción llega a ser secundaria cuando menos; incluso se plantea el ponente hasta qué punto el consumidor requiere o siente necesitar dicha prescripción: los modos de consumo actuales, incide, llevan a que los consumidores se centren en la búsqueda de elementos de su interés ante la abundancia y riqueza cuantitativa de la oferta.

El algoritmo ha matado al prescriptor, señala Guillot, pues la abundancia de la oferta lleva a que la prescripción sea irrelevante para el consumidor, todo lo cual tiene que ver con la pérdida del espíritu crítico general en la que nos encontramos, de lo cual el cine y el audiovisual no son una excepción; de todo ello pondría el conferenciante diversos ejemplos para ilustrar su argumentación desde su experiencia profesional y personal, especialmente como director de festivales de cine, con prácticas incluso contaminadas que no redundan en beneficio de la interacción entre cine y consumidor.

Puso de manifiesto por ejemplo, que en materia de crítica y desde la perspectiva de lo digital, lo importante no es hacer la crítica más sólida, sino ser el primero en hacerla, por el inmediato acceso de los consumidores a los medios digitales y con ello a la información, lo que lleva a que lo cuantitativo perjudique gravemente lo cualitativo. Asimismo señaló la inmediatez del impacto de la transmisión de la información gracias al mundo digital, pero a la vez la forma en que se transmite dicha información, que puede repercutir de un modo totalmente contrario al esperado o a aquel desde el que fue concebida dicha información.

Sobre el peso de las redes sociales en el contexto de la sociedad actual, señalaría cómo hay producciones cinematográficas que se sirven de las redes sociales para hacerse publicidad, algo alejado de los modos y huecos tradicionales y habituales.
Uno de esos "huecos" es el de los festivales de cine, donde los espectadores y los autores pueden disfrutar de una cierta conexión cuando no incluso de inmediatez, amén de que los festivales ofrecen cine inédito, un contenido inédito que, por tal, por su exclusividad, movilice a los espectadores, especialmente cuando gracias a la realidad digital y online el público (especialmente el joven) se mueve en otros circuitos y por otros estímulos.

En este sentido, E. Guillot señaló cómo hay, y debe haber, otros planteamientos de acceso al cine, recordando cómo él mismo descubrió un determinado cine gracias a la televisión, ya que el mismo no se distribuía en nuestro país; así, señaló cómo los festivales grandes están comenzando a premiar películas de plataformas online, y cómo las plataformas online también busca esa interacción con el cine.

El cine, señaló el ponente, puede acabar siendo como el vinilo: es imprescindible la convivencia y la interacción entre los distintos medios, modos y formas de consumo del audiovisual; en lo que respecta a la cultura cinematográfica estamos abocados a la exploración de fórmulas nuevas.

Ángel Cazorla intervino al concluir la ponencia de E. Guillot planteando que existe un déficit cultural (en la gramática, en la sintaxis, pero no sólo ahí) que impide que el público pueda incluso comprender el discurso cinematográfico en su conjunto; pone de manifiesto el profesor Cazorla la posible paulatina desconexión entre los hábitos, gustos y expectativas del público y el cine, a lo que Guillot respondería que corremos el riesgo de caer, salvedades hechas, en involución (y no sólo en el cine) ante la pérdida de background (por parte del cuerpo social), poniendo de manifiesto cómo se confunde "cultura" y "entretenimiento": deglutimos la cultura y la consumimos, pero confundiendo términos entre "cultura" y "entretenimiento", algo que Guillot puso en relación con la rapidez (la inmediatez) del consumo, frente a un consumo cultural que tiene que llevar aparejados el análisis y la reflexión, frente a la inmediatez del entretenimiento.

Cerrada esta ponencia, A.J. González Rueda daría paso a la siguiente píldora del proyecto, a cargo de Susana Gil de Reboleño, de la UCA, tras la cual se produciría, a partir de las 12:50h., el diálogo "Espacios y Prácticas Culturales" sostenido por Héctor García Barnés (periodista en "El Confidencial") y Daniel Mantero Vázquez (gestor cultural, creador artístico y teniente de alcalde de Cultura del Ayuntamiento de Huelva), presentados por el mismo A.J. González. 
González Rueda centró el diálogo en los equipamientos culturales, pidiendo a ambos ponentes su respectiva visión sobre esta realidad clásica en materia cultural en Andalucía, cediendo la palabra en primer lugar a Daniel Mantero, quien comenzaría su intervención agradeciendo la invitación a participar en este seminario a los coordinadores del mismo.

Mantero Vázquez, ahora en funciones de gestor político público, señalaría la importancia de los contenedores culturales a la hora del diseño y la ejecución de las políticas culturales; se detuvo a considerar el (mal) estado de las infraestructuras culturales de la ciudad de Huelva cuando el equipo político del que forma parte tomó las riendas de la gestión en la citada ciudad, lo que les llevó a trabajar inmediatamente en dicha cuestión, incidiendo en el estado y funcionamiento de dichos equipamientos culturales, mejorándolos y aumentando la situación y el volumen y número de dichos espacios.

Mantero señaló la fricción entre realidad y presupuestos públicos, lo que lleva a que en un mandato de cuatro años se hace muy difícil desarrollar un proyecto cultural que deba, además, hacer frente al estado (generalmente no positivo) de las instalaciones culturales, que son una herramienta imprescindible para el desarrollo de las políticas culturales.

A continuación, Héctor García inició su intervención agradeciendo también la invitación a participar en el curso, tras lo cual puso sobre la mesa el papel de los ayuntamientos como servidores y garantes de la política cultural de proximidad. Tras esta breve intervención A.J. González planteó la cuestión del futuro de los equipamientos culturales tradicionales, a lo que el mismo García Barnés señalaría que los equipamientos culturales son herramientas maleables y reconfigurables, lo que puede ser garantía de su supervivencia, pese a lo cual los nuevos públicos culturales, más volcados sobre las realidades virtuales, pueden no sentirse afines a los espacios cultuales tradicionales y ello naturalmente redunda en perjuicio de estos equipamientos físicos.

Daniel Mantero, por su parte, expuso la necesidad de compaginar lo físico con lo online, así como la fuerte vinculación de los mismos con la política real local, que son un activo potente de los gobiernos locales y de la implementación de las políticas culturales en ámbito local, así como de la interacción entre los referidos gobiernos locales y el tejido social y cultural local. Los espacios "clásicos", de acuerdo con Mantero, van a perdurar aunque sea adaptándose a las nuevas realidades y usos del consumo cultural.
A.J. González, moderador del diálogo, plantearía la posible vinculación de los espacios culturales tradicionales a determinados segmentos de edad en el cuerpo social, con un marcado envejecimiento de los públicos culturales ligados a las formas tradicionales de expresión de las acciones culturales, en lo que abundaría en su respuesta Héctor García, planteando casos de su personal conocimiento en la Comunidad de Madrid; en este sentido, el mismo ponente hablaría de la "cultura del acontecimiento", esto es, de cómo las acciones culturales pueden estar ligadas a la generación de dichas acciones como "acontecimientos culturales" (la cultura del "hype", señaló), lo que puede estar ligado a su vez a la pervivencia de los espacios culturales tradicionales, vinculados a la misma vez a esta "cultura del acontecimiento".

Intervendría Salvador Catalán en este momento planteando si las instituciones (públicas) no van un poco "por detrás" en este tema de los espacios y las prácticas culturales respecto al segmento privado, con unas industrias culturales que están trabajando por sacar las acciones culturales de los espacios tradicionales y unirlas a espacios no convencionales, señalando asimismo el progresivo peso de los espacios culturales privados: el ocio privado ha generado nuevos discursos, llevando el consumo cultural al ámbito privado de los usuarios, todo lo cual está profundamente ligados a los nuevos modos y contenidos culturales; señalaría Catalán igualmente la difícil conjunción y el complicado encaje de los equipamientos y políticas tradicionales con estos nuevos modos, usos y contenidos del consumo cultural, por no hablar de las manifestaciones culturales, caso del grafitti, cuya evolución, tan rápida, no está aún canalizada hacia unos espacios culturales tangibles; todo ello, insistió, sin pasar por alto los nuevos espacios -no tradicionales- para la acción cultural.

Daniel Mantero, al hilo de lo expuesto por Salvador Catalán, apuntó en la línea de que las administraciones públicas acaso deberían dejar la dirección de las políticas culturales locales en manos de los creadores y del cuerpo social, desde el fomento de la participación; igualmente señalaría, en la línea de lo señalado por S. Catalán, cómo, desde su perspectiva, los espacios privados se han convertido en un referente imprescindible para los consumos culturales, desde lo cualitativo tanto como desde lo cuantitativo; finalmente señalaría la acuciante necesidad de aunar cultura y público joven desde las políticas culturales públicas locales, así 
como de crear públicos culturales desde la iniciativa pública, sin entrar en conflicto con los hábitos culturales de los nuevos públicos.

Héctor García, tras la pregunta a él formulada sobre los intereses de los medios de comunicación, hablaría -como se ha expuesto en anteriores intervenciones- sobre la dicotomía "cultura" y "entretenimiento", señalando cómo en lo que atañe a su propio trabajo como periodista, la cultura va teniendo cada vez menos espacio ("lo que no vende no se compra", señalaría), especialmente en los grandes medios generalistas frente a lo que sucede en los contextos de menor escala donde la cultura del click o la cultura del evento no necesariamente imperan.

Cerrando este diálogo, Daniel Mantero señalaría -en la línea de lo expuesto por García Barnés- que en contextos locales pequeños, es posible aún desarrollar políticas culturales no enteramente mediatizadas por la cultura del click, aunando programas de difusión y deslocalización cultural (alejados del cortoplacismo) con ofertas de gran formato (como los grandes festivales, tan presentes en la mañana de hoy), todo lo cual conforma el conjunto de las ofertas culturales de una ciudad como Huelva.

A.J. González Rueda daría por concluido este diálogo, tras lo que se pasaría a la siguiente píldora informativa del proyecto y al último diálogo de la sesión del jueves 15 de julio de 2021. Dicha "píldora" correría a cargo de Carmen Rodríguez Reinado, de la UHU, y tras la misma comenzaría el diálogo "Medios de comunicación y prácticas culturales", a cargo de Charo Ramos (jefa de Cultura de "Diario de Sevilla") y de Óscar López (director y presentador del programa "Página 2", de RTVE), que sería moderado por Salvador Catalán, quien introdujo la actividad y presentó a los ponentes.

Como todos los ponentes anteriores, Óscar López comenzó dando las gracias a la organización por la invitación a participar en este seminario, señalando tras ello que nos encontramos ante un momento complicado para la prensa cultural, cediendo la palabra a Charo Ramos, quien apuntó que en efecto nos encontramos ante un panorama sombrío que necesita cierto humor para su análisis y consideración;

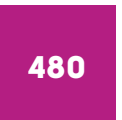
expuso así el progresivo "adelgazamiento", cuando no desaparición, de los espacios y secciones de cultura en el ámbito de la comunicación, una forma de señalar de nuevo (como otros ponentes) la dicotomía entre "cultura" y "entretenimiento" cuando, además, nos encontramos ante la gran transformación por (y hacia) el mundo digital en lo que se refiere a los medios de comunicación, en general, y en el ámbito de la comunicación cultural en particular.

La ponente abogó por los criterios de excelencia (frente a una inmediatez no siempre positiva) en el ámbito del periodismo digital, por la apuesta por la excelencia frente a lo que denominó la "dictadura del click", una apuesta por la excelencia que se sustenta en buena medida en la labor crítica de la prensa así como en el acompañamiento a los creadores y artistas, cuando las redes sociales, señaló, lo están invadiendo todo, incluido el tiempo de lectura de los consumidores culturales.

Junto a la situación dramática de los medios escritos, expuesta por Charo Ramos, Óscar López señalaría que en el marco televisivo la situación no es mucho mejor, con un periodismo cultural en los medios audiovisuales abocado casi al activismo cultural, con profesionales que son esclavos del "share", la audiencia, compitiendo con programas de entretenimiento en una competencia imposible, pese a lo cual la cultura está y debe estar presente en los medios audiovisuales en un mundo globalizado donde los formatos son franquicias universales que "educan" en uno u otro determinados sentidos a los espectadores en todo el mundo.

Abundó el ponente en la importancia de la prescripción (una idea recurrente en los conferenciantes de la sesión) y la crítica cultural, frente a una realidad en la que los espacios culturales (profesionales incluidos) que deben soportar la losas pesada de una pelea desigual con las ofertas de entretenimiento y un permanente peligro de recorte o incluso de desaparición, frente a lo cual La 2 de RTVE aparece, de acuerdo con el conferenciante, como un verdadero oasis.

Charo Ramos por su parte expuso la necesidad de atender nuevas realidades culturales, al tiempo que mencionó también la reducción del papel en la comunicación de la prensa cultural, así como la competencia de los contenidos de cultura con otros espacios, como el reservado a las cofradías; mencionó asimismo el impacto del "share" en el espacio digital, con el cómputo de los lectores como factor de incidencia en la organización de las secciones, incluidas naturalmente las culturales. Apoyándose en los datos expuestos por el profesor Pérez Yruela, la ponente habló de la reducción de la inversión de las instituciones públicas andaluzas en materia 
cultural, lo que incide, apuntó, negativamente asimismo en la comunicación cultural en Andalucía, todo ello bajo el peso de la dictadura del click ya citada.

Óscar López a continuación señalaría cómo las cadenas privadas se sustentan sobre frecuencias de emisión que son públicas, lo que -según el ponente- podría llevar a que se solicite a los gobiernos que las cadenas privadas aborden más contenidos culturales en sus emisiones, incidiendo además en cómo la política marca los tonos de la difusión cultural; en este sentido, expuso cómo ha visto desaparecer programas de contenido cultural en distintos medios públicos de comunicación, produciéndose un retroceso (que acaso puede conjugarse con la involución que mencionaba Eduardo Guillot en su ponencia, con anterioridad) frente al estado de cosas de momentos anteriores, cuando los contenidos culturales en las televisiones públicas eran (cuantitativamente al menos) superiores a la realidad existente hoy día. Señaló igualmente que nos encontramos en un momento de transición de lo analógico a lo digital, que está siendo especialmente duro en lo que atañe a la prensa escrita, lo que corroboraría Charo Ramos, exponiendo cómo se han perdido espacios, como determinados suplementos culturales, sin alternativa ni continuidad.

La misma ponente, en la línea de lo expuesto con anterioridad en la sesión, apuntó que todas las webs son deficitarias (como manifestó Santi Carrillo), y señaló, como también se ha venido diciendo en la sesión de hoy, que la cultura no puede ser gratuita, que los profesionales (creadores, comunicadores...) deben cobrar por su trabajo, a lo que Óscar López añadió que en efecto la cultura no puede ser gratuita, como no puede ser gratuito el trabajo del prescriptor, del crítico cultural, lo que se hace aún más acuciante en un momento de transición como se ha señalado que es aquél en el que estamos, cuando lo analógico va desapareciendo frente a lo digital, con unos periodistas una vez más tildados por López como activistas culturales y con unos periodistas culturales cuya labor es puesta en solfa por determinados modos y usos, y usuarios (cuando no empresas) del mundo digital.

Intervendría Salvador Catalán cerrando el diálogo resumiendo las últimas intervenciones de ambos ponentes, agradeciendo su participación en el seminario, tras lo cual A.J. González Rueda abrió un breve turno de palabra de cierre a los coordinadores e intervinientes de la sesión de hoy, invitación que fue aprovechada por Ángel Cazorla para señalar el alto nivel de las ponencias de la mañana y para agradecer a los conferenciantes el trabajo realizado, al tiempo que Jacinto Porro hizo uso de la palabra igualmente para ponderar el formato empleado, enteramente digital, en este curso, y para invitar, como hiciera Cazorla en su intervención a ponentes y a asistentes a conectarse en la sesión del viernes 16 de julio, a las 09:30h.

La segunda sesión del seminario daría comienzo el viernes 16 de julio de 2021 a las 09:30h. con la conferencia "Cultura y Universidad: balance de la dimensión cultural", a cargo de Antonio Ariño Villarroya, catedrático de Sociología en la Facultat de Ciències Socials y exvicerrector de Cultura e Igualdad de la Universitat de València, quien fuera presentado por Antonio J. González Rueda, quien volvería a invitar a los participantes a servirse de las herramientas de la plataforma online sobre la que se implementa el seminario para hacer sus contribuciones al desarrollo del mismo tras exponer el perfil profesional e investigador del ponente como sociólogo y como gestor en el ámbito universitario.

El profesor Ariño realizaría una reflexión complementaria a su participación en el proyecto de investigación que centra los intereses del curso, abundando en las ideas desarrolladas por él en su trabajo, abordando una serie de cuestiones dimanadas del mismo, en torno a su libro "Políticas para la alma mater".

Qué es cultura universitaria es la primera de las cuestiones planteadas por el ponente, quien señaló que una de las tareas de la universidad, junto a la docencia y la investigación es la de la extensión de la cultura universitaria, desde la crítica, la creatividad, la actualidad, la ciencia y el marco académico, que son las 5 características de una cultura universitaria cuyos destinatarios son los estudiantes, la comunidad universitaria y la sociedad como conjunto, un tridente in crescendo que es debe ser el objeto de atención por parte de la cultura universitaria. Todo ello se debe hacer para completar la formación que los títulos universitarios (de Humanidades, CGSS, Ciencias e Ingenierías) en sí no dan, no ofrecen, en lo que se refiere a la formación integral de la persona, y debe hacerse a partir de la participación (desde un triple prisma: personal, social y ecológico) y primando la idea de la horizontalidad, poniendo en juego el tridente de los recursos, las competencias y las disposiciones, pues la participación cultural debe relacionarse con la forja de disposiciones, de de maneras de 
ser (propensiones, tendencias, inclinaciones para actuar, sentir, percirbir..., citando el ponente a Lahire, 142).

Señalaría el ponente las competencias de extensión y cultura universitaria en el ámbito de las universidades españoles de acuerdo con lo observado por las propias universidades del país, al hilo de lo cual A. Ariño apuntó que hay mucho que mejorar en este sentido, pues se muestra un esquema que tildó de "raquítico" aún y que debe cultivarse y crecer, como se desprende por ejemplo de la baja percepción de las unidades de cultura científica e innovación, las unidades de igualdad, los programas de formación integral del alumnado o el voluntariado y la cooperación en el ámbito de las universidades de España.

Hablaría el profesor Ariño también de la necesidad de coordinación de la oferta de las universidades españolas en materia de cultura, de la falta de una perspectiva común armonizadora en este contexto, así como del papel central del personal técnico en materia de cultura en las universidades españolas, señalando que la UCA constituye un buen ejemplo en este sentido.

Un factor a considerar es el de cómo incluir todo lo anterior en el currículum académico, haciendo hincapié en el problema de la mercantilización, frente a la necesidad de poner en valor que "existen valores que son fines por sí mismos" (citando a N. Ordine): en este sentido es imprescindible que la cultura y el ámbito de la gestión cultural tengan la relevancia que les corresponde en el marco universitario, de modo que (como señalase Fichte) las personas que se desenvuelven en el ámbito de la universidad puedan aprender y practicar el arte de aprender, para todo lo cual lo mejor es contar con un servicio cultural que observe la realidad, como sucede con el Observatorio Atalaya en Andalucía, cuyo trabajo permitirá actuar mejor sobre el territorio de manera que además, sabiendo ya en qué consiste la cultura universitaria, se puedan implementar los mecanismos y herramientas para dichos fines.

Con esta reflexión dio fin a su intervención en profesor Ariño, tomando la palabra el profesor González Rueda, quien preguntó al ponente por su percepción de la dimensión cultural de la universidad desde la autoridad que le confiere su experiencia y su trayectoria, pregunta a la que el conferenciante señaló que es imprescindible que las universidades "se crean" lo que apuntan en su marco teórico, de modo que la tercera misión de la universidad sea verdaderamente el ámbito de la cultura universitaria, generando así disposiciones para mejorar la sociedad e incluso para cambiar el mundo, especialmente en un contexto general como el actual, cuando el espíritu crítico y la capacidad de reflexión y diálogo parecen encontrarse en franco retroceso y cuando el sector cultural se enfrenta a grandes retos (como los representados por un mundo del entretenimiento cada vez más alejado de la cultura); falta integración, señaló Ariño, siendo imprescindible que se rompan las fronteras interiores de la comunidad universitaria.

Antonio J. González señalaría también un giro en el concepto de participación frente un menor peso de cuestiones como el compromiso ante el concepto de asistencia; en este sentido apuntó que sería necesario trabajar más en base a proyectos, lo que fomentaría la participación y el compromiso, frente al mayor peso de la asistencia; el profesor Ariño comentaría que la asistencia, la implicación activa y el compromiso son en realidad tres estadios de la participación, que se gradúa en esos tres niveles combinables los cuales interactúan en función de los intereses y los momentos del individuo.

Se plantearon cuestiones en torno a la necesidad de la formación del PAS universitario, señalando a este respecto el ponente que la formación es imprescindible siempre, y que es necesaria una formación in itinere, y sobre el valor de la cultura para el ser frente al tener, y sobre la tercera misión universitaria en torno a la cultura así como sobre el compromiso, haciéndose ver la necesidad de enfatizar entre los estudiantes la complejidad y riqueza del ser universitario, ante lo cual el profesor Ariño señalaría que es imprescindible trascender del tener y abundar en el ser y en las disposiciones desde el ámbito universitario.

Cerrada esta ponencia se transmitirían la primera "píldora" del proyecto de la sesión del 16 de julio, a cargo de Pedro Jesús Luque Ramos (UCA), tras lo cual tendría lugar la ponencia de Tristán Pertíñez Blasco, director gerente del Centro de Estudios Andaluces (CENTRA), Consejería de la Presidencia, Administración Pública e Interior de la Junta de Andalucía, que llevaría por título "Jóvenes y prácticas culturales: una visión desde Andalucía”, siendo presentado por otro de los coordinadores del seminario, el profesor Ángel Cazorla Martín, quien destacó los perfiles internacionales y de gestión del ponente.

T. Pertínez comenzaría su disertación sobre el binomio jóvenes andaluces y prácticas culturales agradeciendo 
a la UCA la iniciativa de este seminario; comenzaría su intervención con una amplia exposición del enfoque de su ponencia desde la Fundación CENTRA, que cumple en 2021 veinte años de existencia siendo el centro de referencia en la investigación en ciencias sociales en Andalucía, volcada en generar conocimiento científico y difundirlo en la sociedad andaluza desde distintas perspectivas y desarrollando proyectos y premios de investigación, cursos de especialización y estudios sociológicos amén de históricos, amén de participando en proyectos europeos desde el ámbito andaluz. Guenta el CENTRA con un ecosistema exhaustivo de información, con grupos de expertos, consultas a la ciudadanía, y con el desarrollo de investigación cualitativa y cuantitativa.

Tras plantear asimismo un esquema de la población andaluza por grupos de edad (8.464.411 personas, según el IECA 2020); el segmento de interés de la ponencia (andaluces de 15 a 34 años) comprende a uno de cada 4 andaluces aproximadamente, con una ligera preeminencia de hombres frente a las mujeres $(26 \%$ / 24\%). De acuerdo con el barómetro andaluz de junio de 2021 (24 de junio, menos de un mes de distancia de tiempo respecto al desarrollo del seminario), un $78^{\prime} 2 \%$ y un $80^{\prime} 1 \%$ de los andaluces entre 18-24 (primer dato) y entre 25-34 años (segundo dato) se consideran consumidores habituales de cultura, presentando dichas franjas de edad los datos más altos de la población de Andalucía en lo que se refiere al consumo cultural, con mínimas diferencias por sexos en ambos grupos de edad.

Hecha esta misma pregunta desde el CENTRA en el barómetro de junio de 2020 se observa una evolución significativa, siendo que son más los jóvenes andaluces que reconocen consumir cultura en 2021 que en 2020, lo que el ponente pone en relación con el desarrollo de la pandemia del covid19, incrementándose el consumo cultural a causa de la misma.

Entre los elementos más consumidos por los que dicen consumir cultura se encuentran en primera posición los libros, seguidos por el cine, música, teatro y exposiciones, conciertos, TV, documentales, viajes, monumentos, series..., todo lo cual muestra los intereses de consumo cultural de los jóvenes andaluces entre 18 y 34 años tanto se trate de un contexto físico como de un contexto digital. Se preguntó por el consumo cultural antes de la pandemia, con una respuesta mayoritariamente positiva especialmente en el segmento comprendido entre los 18 y los 34 años; el consumo de inter- net, señaló el ponente, ha aumentado especialmente entre los jóvenes de dicha franja de edad en el marco de la pandemia.

Se detuvo el ponente a considerar el tipo de uso de internet hecho por los jóvenes andaluces, la mayor parte de los cuales sostienen utilizarlo para leer, en un contexto como el actual en el que el papel parece encontrarse en retroceso frente a la lectura en soporte digital, que se está generalizando y extendiendo si bien no supone aún una amenaza para los elementos tradicionales físicos en los que se distribuye la cultura (sic).

Con estas consideraciones sobre las actitudes de los jóvenes andaluces sobre el consumo cultural concluiría el ponente su disertación, interviniendo a continuación el profesor Cazorla, su presentador, quien señalaría que es de interés poner en conexión las líneas de trabajo del Observatorio Atalaya con las del CENTRA, con vistas a armonizar y abundar en el conocimiento sociológico de Andalucía, señalando el ponente la oportunidad de lo señalado por A. Cazorla con vistas de conseguir una mayor y mejor comprensión de los comportamientos de la población andaluza, especialmente en lo relativo al consumo cultural. El ponente concluiría su intervención abundando en su exposición sobre algunas de las líneas de trabajo del CENTRA, como su nueva revista de ciencias sociales cuya aparición está prevista para el año 2022, así como manifestando su consideración positiva en relación con el guante lanzado por el profesor Cazorla sobre la posible cooperación entre ambas entidades, CENTRA y Atalaya, algo que ponderaría asimismo el profesor González Rueda.

Tras una breve pausa tendría lugar la conferencia "La lectura como práctica cultural" impartida por Eva Díaz Pérez, directora del Centro Andaluz de las Letras (CAL) de la Consejería de Cultura y Patrimonio Histórico de la Junta de Andalucía, precedida por la siguiente "píldora" del proyecto, a cargo de Adelaida Ruiz (UCA). La directora del CAL sería presentada por A.J. González Rueda, quien le pediría que reflexionase en torno a lectura, autores y políticas públicas tras dibujar los perfiles profesionales de la ponente, periodista cultural, escritora con muchos lectores y muy premiada y ahora gestora -desde el CAL- de las letras andaluzas.

La conferenciante abrió su intervención manifestando lo oportuno del seminario y de este 
espacio de reflexión y debate, tras lo cual expuso la complejidad de las líneas de acción del CAL, su implicación e implementación en todo el territorio andaluz, extenso y heterogéneo, con un sentido muy democrático de la cultura inspirado en las Misiones Pedagógicas de principios del siglo XX, señalando cómo la pandemia impactó en el GAL y en el desarrollo de su trabajo a comienzos del año 2020. Frente a la caída de unas acciones y programas, el CAL reaccionaría potenciando otros donde y como posible, caso de los clubes de lectura, con especial incidencia en el trabajo desde el ámbito virtual, caso del desarrollo de encuentros virtuales o la escuela de jóvenes escritores, que incide en jóvenes entre 12 y 20 años, que genera espacios donde los jóvenes escritores pueden encontrarse y reafirmar su vocación, todo lo cual se ha visto afectado por la pandemia del covid19, quedando la escuela en suspenso en 2020 y 2021 por causa de la misma. Pese a ello, se ha fomentado la modalidad online de los encuentros virtuales entre jóvenes creadores, de modo que se ha buscado implementar vías que suplan a los caminos momentáneamente cortados por la pandemia.

Señaló la ponente que se ha generado una mediateca en el CAL y se ha buscado reactivar muchas de las actividades, en la medida de lo posible desde el otoño de 2020, notándose un anhelo de presencialidad entre los públicos del Centro. Entre estos programas que se han lanzado está el de "Conversaciones en el Museo", sacando la Literatura de sus cauces habituales y llevando el consumo del Patrimonio hasta otras formas de expresión, citando a los escritores en museos, aunando el patrimonio literario con el patrimonio histórico, viéndose dicho programa afectado por las consecuencias de la pandemia; en cualquier caso, insiste la ponente, la incorporación de las nuevas tecnologías al desarrollo de los programas del CAL ha sido fundamental.

Otro de los programas desarrollados ha sido el de los paseos literarios, que busca descubrir las presencias literarias en las ciudades andaluzas por las que pasaron o donde vivieron grandes figuras de la literatura; este programa ha tenido una gran repercusión, llegando a ser incluso el único programa que el CAL podía implementar al desarrollarse al aire libre.

La ponente señaló que los libros se han constituido en un pilar en el consumo cultural durante la pandemia; en ese sentido apuntó que el año 2020 no ha sido un muy mal año en la venta de libros en Andalucía, incorporándose muchos lectores como señalaban los datos del barómetro del CENTRA, especialmente entre los más jóvenes, interesados por un perfil determinado de libros; al hilo de este razonamiento la directora del CAL apuntaría que es necesario atender a las necesidades y preferencias lectoras del público más joven, de cara al fomento de la lectura.

La ponente daría paso a la posibilidad del debate, con las preguntas que surgieran de entre los asistentes, al hilo de lo cual su presentador, A.J. González le preguntaría por su punto de vista como escritora, como periodista y como gestora del CAL sobre las perspectivas de la lectura en el marco de Andalucía; en respuesta, la ponente hizo hincapié en la dimensión digital de la lectura ante la evidencia del mapa digital del que están dotados los más jóvenes, siendo que la situación extrema a la que nos ha abocado el covid19 ha hecho aún más evidente esta cuestión, de modo que la tecnología debe incorporarse a nuestros programa culturales, en paralelo a lo presencial (sic). Han de implementarse y formularse nuevos formatos mixtos, reuniendo Literatura e Historia, por ejemplo, poniendo el ejemplo del trabajo desarrollado en la Casa de Murillo de Sevilla, donde se aúnan Literatura y otras artes. Tecnología y lectura aunadas son, de acuerdo con la conferenciante, un ejemplo de los muchos y nuevos caminos a desarrollar, en buena medida mixtos, ante el mundo actual y las perspectivas del futuro en materia de consumo cultural. Todo ello sin perder el encuentro entre autor y lector y fomentando la interacción, en la medida de lo posible presencial, entre creadores y consumidores de literatura.

A.J. González, cerrando la ponencia tras agradecer su participación en el curso a Eva Díaz, animó a la directora del Centro Andaluz de las Letras a seguir trabajando en el repositorio audiovisual de autores, la Mediateca del CAL, y a los participantes en el seminario a darse de alta en ebiblio, el préstamo de libros virtuales vigente en la red de Bibliotecas de Andalucía.

Tras la pausa prevista en el programa tuvo lugar el primero de los diálogos de la sesión, titulado "Lectura, autores, patrimonio literario y prácticas culturales", a cargo de Fernando Zamácola Feijoó, director gerente de la Fundación Delibes, y Marcelino Sánchez Ruiz, director de la Fundación Legado Literario Miguel Hernández, encuentro que sería moderado por Antonio J. González Rueda. Dicho 
diálogo fue precedido por la tercera "píldora" del proyecto, que corrió a cargo de Rosalía Martínez García (UPO).

El moderador presentó a los ponentes, responsables de las dos fundaciones literarias, dijo, más innovadoras y con mayor adaptación a las viejas y nuevas prácticas culturales, la Fundación Delibes y la Fundación Legado Literario Miguel Hernández; ambos ponentes agradecieron las palabras del moderador dando comienzo a su diálogo partiendo de la reflexión sobre el trabajo de sus instituciones en materia de lectura y de las actividades culturales que desarrollan las mismas y sobre cómo se están enfrentando ambas fundaciones a la situación actual, con el covid y la transición al mundo digital.

Fernando Zamácola intervino en primer lugar agradeciendo la invitación a participar en el curso y señalando que para su institución ha sido vital adecuar sus objetivos a la realidad presente (conservar, difundir e investigar el legado que conservan), incluyendo un nuevo objetivo cual es el de generar reflexiones en la sociedad a partir de las preocupaciones e intereses de Miguel Delibes, lo que ha generado un espacio de reflexión y debate que en realidad trasciende de los propios límites iniciales de la idea.

Han estructurado unas líneas estratégicas de acción en torno a las cuatro inquietudes esenciales e intereses de Delibes: la defensa del mundo rural, la defensa de la infancia, la defensa del medio ambiente y la defensa de los desfavorecidos y la denuncia de las desigualdades desde una perspectiva de justicia social; dichas líneas rectoras se imbrican con los perfiles del autor y sirven para tejer una malla que sirve para vertebrar el trabajo de la Fundación.

Igualmente han desarrollado una línea de acción en formato digital frente a la pandemia, una digitalización entendida en términos herramentales, buscando por ejemplo nuevas audiencias que tienen que ver con los segmentos más jóvenes del público cultural, pero no sólo de este segmento más joven, ya que las herramientas digitales pueden ser de gran ayuda para otros sectores de edad del consumo cultural. Asimismo han cambiado la forma de medir el desempeño de su actividad, los baremos de evaluación del trabajo realizado.

Marcelino Sánchez, a continuación, ponderó el trabajo de la Fundación Delibes y la exposición realizada por F. Zamácola, tras lo cual realizó un breve histórico sobre la Fundación Legado Miguel Hernández, que surge a partir de una determinada realidad de gestión producida a comienzos de la pasada década, cuando la Diputación de Jaén (a través del Instituto de Estudios Jiennenses) cobija inicialmente el Legado de Miguel Hernández con el acuerdo de la familia del poeta para luego convertirse en titular del mismo, dignificándolo y poniéndolo en valor para finalmente crear la Fundación en 2017. M. Sánchez apuntó la incidencia de la pandemia en el trabajo de la Fundación, apenas comenzado, que sería llevada a un inmediato cambio en sus incipientes estrategias de acción, generando por ejemplo "píldoras" breves sobre el autor como medio de divulgación de su figura y su obra.

Una de las líneas de acción, por ejemplo, la de fomento de las visitas al museo, se vendría abajo temporalmente, pero ello no impidió explorar otras fórmulas como los talleres poéticos infantiles, con niños entre 8 y 12 años articulados en dos talleres por edades, con Miguel Hernández como pieza de animación a la creación no solamente en el sector infantil, sino también orientando dicha acción a poetas y creadores en otros ámbitos del arte, siempre buscando ubicar al poeta en un espacio rabiosamente contemporáneo desde una enorme diversidad de enfoques, un proyecto que encontrará continuidad en el futuro.

La Fundación está trabajando, como señalase el profesor Ariño en su ponencia, en la idea y la línea del "colaboratorio", el trabajo conjunto con otras instituciones, entidades y creadores, que se ha plasmado por ejemplo, en la creación de un espacio de creación literaria, una revista, donde artistas de diferentes perfiles encuentran un ámbito de expresión destinado a todo tipo de públicos; la Fundación, además, está generando una Mediateca propia, documentando sus acciones culturales de cara a la proyección presente y futura de su acción, para lo cual ha sido fundamental la colaboración con la UNED.

F. Zamácola por su parte señaló cómo ellos igualmente huyen de lo efímero, buscando la permanencia y el acceso a otras audiencias dejando constancia del trabajo realizado pensando en el usuario asíncrono; asimismo apuntó el interés de su entidad por lo interdisciplinar; respecto a los mecanismos de evaluación, cuestión antes apuntada, el ponente señalaría cómo es necesario buscar la retroalimentación de los usuarios, conociendo su experiencia como tales de cara a mejorar el trabajo de la institución y la toma de decisiones de la misma. En último extremo apuntaría Zamácola también 
en el sentido de los valores, en este caso los de Miguel Delibes, que son la amalgama del trabajo de su Fundación y la referencia vehiculadora de la acción de esta entidad cultural.

Marcelino Sánchez haría a su vez hincapié en la cuestión de los valores del autor, en su caso de Miguel Hernández, como herramienta articuladora del trabajo de su institución, liberando y enriqueciendo incluso los perfiles del poeta murciano y contribuyendo a su mejor conocimiento por parte del público. En este sentido, la Fundación jiennense está diseñando un programa para trabajar con personas privadas de libertad, animándoles a leer e incluso a crear, apoyándose en los perfiles del poeta especialmente en sus últimos años de vida.

Fernando Zamácola señalaría que si bien las fundaciones culturales son a menudo consideradas como agujeros de dinero (sic), debe primar la función social de estas instituciones y su consideración como agentes transformadoras a través de su trabajo y de su acción sobre la ciudadanía, muchas veces articuladas incluso desde un espíritu (en el caso concreto de su entidad) lúdico como modo de atraer a sectores más amplios de la población. Una iniciativa de la Fundación ha sido la de motivar a los más jóvenes a escribir cartas de puño y letra a Delibes y/o a la Fundación como modo de fomentar la interacción con dicho segmento de la sociedad: han recibido 12.000 cartas de niños de Castilla-León, sirviendo dicha acción para acercar a los niños a la figura de Delibes.

Para cerrar este diálogo, Marcelino Sánchez puso el acento en las cuestiones planteadas en su diálogo con $\mathrm{F}$. Zamácola, incidiendo en la grandeza de la lectura como vehículo de conexión individual con el mundo que nos rodea y como modo de generar inquietudes en los lectores, al tiempo que Zamácola incidió en el papel de las nuevas tecnologías en el momento actual como herramienta de conexión y aprendizaje así como en la vinculación con los usuarios, con el público que disfruta con el trabajo de sus entidades, como forma de mejorar el trabajo realizado y a realizar, tejiendo una red de apoyo comunitario sobre la que las entidades culturales se sostienen.

Proyectada la siguiente "píldora" del estudio, a cargo de Daidee Veloz Cañete (UPO), tendría lugar la conferencia titulada "Sociedad digital, ¿nuevas? Tecnologías y prácticas culturales", impartida por Paulo Carlos López López, politólogo y pro- fesor de la Universidad de Santiago de Compostela y coordinador de la ICOMTA'21 (Conferencia Internacional de Comunicación y Tecnologías Aplicadas), que sería presentado por Ángel Cazorla quien destacó su perfil como conocedor de los retos y problemas que tienen que ver con la difusión de la cultura en el mundo digital.

El ponente comenzaría su exposición agradeciendo a la UCA la organización de este curso, tras lo cual entró en la materia de su conferencia con varias grandes premisas que tienen que ver con la interacción entre la sociedad, el mundo digital y las nuevas formas de acción y de expresión de la cultura y de circulación y consumo de la cultura; igualmente trataría sobre la visión y la percepción de la cultura de masas: se ha pasado de la cultura de masas a la cultura de grupos e incluso a la cultura individual; continuaría con una tercera cuestión, que guarda relación con las propias industrias culturales y sus posibles cambios en este mundo digital, con la posible democratización de las prácticas culturales; asimismo trataría sobre la posible continuidad de las prácticas pero sobre soportes diferentes, sobre la práctica cultural y su relación con la identidad, así como sobre las plataformas de expresión de las prácticas culturales en el mundo digital.

Plantearía el ponente si nos encontramos ante un cambio de concepto y de paradigma sobre las industrias y el consumo cultural, señalando que nos hallamos efectivamente en un cambio de paradigma fomentándose nuevas fórmulas que modifican la cultura hegemónica tradicional, algo relacionado con el concepto de "democracia cultural" antes señalado por el ponente, que puede incluir a nuevos bloques ciudadanos en el proceso de construcción y consumo de cultura; el mundo digital presenta un panorama distinto, que puede fomentar la democracia cultural, si bien surgen dudas acerca de si este proceso afecta asimismo a la creación.

Sobre streamers y youtubers, por ejemplo, como manifestaciones de la nueva realidad digital, el ponente plantea la cuestión de si se les puede considerar como un elemento cultural o no, remitiéndose a la Escuela de Franckfurt y su crítica al sistema capitalista original; en este sentido señaló cuestiones como la de la degradación de los lenguajes o la imposibilidad de participación de las clases populares en el ámbito cultural; el ponente abundaría en la cuestión de las tecnologías, la globalización y las prácticas culturales, señalando tópicos como el ¿ocaso? del Estado-Nación, el papel de las identidades y sus prácticas culturales dando sentido a la 
vida de las personas como espacio-refugio ante el abismo de las tecnologías, y el surgir de prácticas culturales de resistencia (de la mano de identidades de resistencia), caso del teatro en América Latina (sic) ante dicha misma realidad abisal, elementos todos ellos objeto de un debate que se acentúa de la mano de las transformaciones de un mundo en transición hacia lo digital.

Abriría el conferenciante un espacio de reflexión sobre las redes sociales y las comunidades digitales, espacios de consumo de información en los que el individuo se integra en un modelo de sociedad digital conformado por personas con intereses comunes en un fenómeno de orientación y de fusión del consumo cultural de los integrantes de dichas comunidades digitales, que crean y canalizan nuevas formas de participación, y sirven como vehículo primero de socialización para las nuevas generaciones digitales; al mismo tiempo presentan nuevas formas de organización y participación en las actividades culturales, así como de expresar las demandas culturales en un proceso que se construye a través de la red.

En un marco de polarización política y social, sin embargo, se asiste a la construcción de valores desde estas comunidades y a un evidente consumo de productos culturales en la red que es breve, ininterrumpido y no excluyente, globalizado pero solitario, afectivo e incidental (el producto viene a nosotros, no es buscado, lo que resta capacidad de decisión al individuo), y es un consumo multipantallas, múltiple y simultáneo.

La sociedad digital y las tecnologías aplicadas cambian el concepto de cultura y la forma de expresión y construcción de las formas culturales, señalando el ponente ámbitos de acción de estos cambios, como el relativo al del Poder y las posiciones de poder en las prácticas culturales, las desigualdades a la hora de participar en la creación cultural, o las fronteras de construcción del relato cultural en la sociedad digital, preguntas que nos llevan a señalar que la sociedad digital ha modificado la cultura pero que queda mucho que hacer aún para que fomente la democratización cultural.

El profesor Cazorla intervendría al término de la ponencia ponderando las líneas de análisis expuestas por el conferenciante y abundando en el polimorfismo de las cuestiones planteadas por P. López en su intervención, haciendo hincapié en lo relativo a los procesos de resistencia ante el mainstream (sic), preguntando al ponente si cree que pueden conformarse redes de resistencia paralelas al ámbito genera- lista del mundo digital; el ponente en este sentido hablaría de la existencia de redes contrahegemónicas, especialmente en el ámbito latinoamericano (sic), señalando que existe cierta capacidad de organizar redes, si bien siempre nos encontraremos ante la cuestión de quién es propietario de los ámbitos de sustento de dichas redes... En cualquier caso, dije entender que es posible la creación de dichas redes y que es esencial considerar que sólo desde la identidad es posible la interrelación y la inteligencia del mundo que nos rodea.

La siguiente "píldora" del proyecto correría a cargo de Elodia Hernández León (UPO), tras cuya proyección se desarrollaría la última acción del seminario, el diálogo sobre "El género en las prácticas culturales" entre Cristina Guirao Mirón, directora del Seminario de Pensamiento y Cultura de la Universidad de Murcia y Fátima Anllo Vento, directora del Observatorio de Creación Independiente, moderado por Jacinto Porro, quien señaló el peso de la sociología en el ámbito del análisis cultural en el inicio de su intervención, pasando a considerar la perspectiva de género en el ámbito de la acción cultural antes de presentar a las ponentes de este diálogo, a las que señaló como pioneras de la gestión cultural en España.

Cristina Guirao señaló cuatro elementos básicos: la brecha digital en el consumo cultural, las formas de participación y consumo cultural, la representación y legitimidad de los bienes culturales producidos por mujeres y los procesos de socialización, consumo y reproducción cultural entre mujeres y hombres. Respecto al primero de dichos elementos, señaló lo evidente de su existencia y lo distinto de su incidencia por grupos de edad en el contexto social en el contexto de este nuevo proceso tecnológico en el que nos hallamos, que está cambiando los consumos culturales con incidencia también por género, con las mujeres menos imbricadas en la transición digital.

Fátima Anllo abundaría en lo expuesto por C. Guirao, apuntando que existe en efecto una mayor práctica en las actividades relacionadas con la tecnología por parte de los hombres, algo que se materializa en el uso de las nueva tecnologías y la prensa digital, así como en general en las actividades usuales en internet, con especial incidencia en el ámbito tecnológico.

Señaló que ello guarda relación con la socialización de la cultura pero también con el tipo de contenidos al alcance de los consumidores, 
poniendo el caso de los videojuegos y sus diferentes temáticas, en lo que incidiría Cristina Guirao; F. Anllo por su parte abundó en el lugar común de la atracción por lo técnico por parte de los hombres como rasgo biológico (sic), lo que sostiene la ponente que es una construcción social y no obedece a ninguna cuestión biológica; en cualquier caso, señalaron las ponentes que los hombres han realizado la transición digital en mayor medida que las mujeres; las mujeres concilian ambos soportes, el físico y el digital en sus prácticas, y consumen más los medios audiovisuales tradicionales como cine, música, libros, teatro...

En cuanto a las formas de participación y consumo cultural, las ponentes señalarían que existe asimismo una gran diferencia entre hombres y mujeres, con participación "débil" y "fuerte" según su vinculación al derecho de participación de la cultura o en la cultura, lo que nos posiciona como consumidores (ámbito "débil") o como ciudadanos (ámbito "fuerte"), con las mujeres esencialmente en un ámbito débil, como consumidoras y como reproductoras en materia cultural, frente a un segmento masculino en un ámbito "fuerte", como creadores en este contexto.

Como ejemplo, F. Anllo señalaría que al frente de las 50 instituciones culturales del país, el $84 \%$ de esos grandes puestos de legitimación cultural están en manos de hombres, con las mujeres apartadas de los puestos rectores de la gestión y por ende con menor legitimidad y representación en el campo cultural, limitadas por el propio sistema, todo lo cual se refleja y se materializa asimismo en la composición de los patronatos de museos, en las Reales Academias, en los jurados de premios, en las instituciones de derechos de autor e intelectual, etc. (sic)., todo lo cual afecta al ámbito de la representación y la legitimidad en el ámbito de la cultura, así como a los procesos de socialización, consumo y reproducción cultural entre hombres y mujeres, todo lo cual se ve afectado por los discursos de resistencia que tratan de impedir la ejecución de mecanismos de integración positiva, como el discurso que vincula la "calidad" al segmento masculino de la población.

Las ponentes señalarían en su diálogo que estos discursos de resistencia afectan asimismo a minorías étnicas, perfiles raciales, así como a la compra de obras de arte creadas por mujeres en los museos, con una pobre representación del arte creado por mujeres en los mismos aún hoy, abundando en la jerar- quización por géneros en materia de colecciones artísticas y de investigación y difusión del arte, con una mayoría de investigadoras mujeres frente a una mayoría de elementos rectores masculinos.

El moderador del diálogo, el profesor J. Porro, intervendría para plantear la cuestión de cómo romper las barreras expuestas por las ponentes, al tiempo que la profesora Guirao señaló que es necesario que los hombres comiencen a entender el universo femenino, mientras F. Anllo apuntaba por su parte que la gran conquista es que toda persona pueda tener las mismas oportunidades para escoger y desarrollar su propio camino, frente a la socialización histórica de los sexos masculino y femenino, con todas sus cargas positivas y negativas ejemplificando la cuestión con la expresión "las mujeres son lo que son, los hombres son lo que hacen"(sic). La profesora Anllo puso el acento en la necesidad de tener las mismas opciones para elegir, frente a las estrategias y arquetipos de división y reproducción de esquemas tradicionales, lo que redundará en beneficio de hombres y mujeres.

A la conclusión de este diálogo se proyectaría la última "píldora" informativa del proyecto y del estudio, a cargo de Rocío Muñoz Moreno (UHU); tras ello y finalmente tendría lugar la sesión de conclusiones y acto de clausura del seminario a cargo de los coordinadores del mismo; tomaría la palabra J. Porro quien valoraría el desarrollo del curso, la alta participación en el mismo y animaría a los inscritos a enviar a la coordinación sus impresiones, conclusiones y valoraciones sobre la actividad; recordaron asimismo el imprescindible papel de todos quienes que han hecho posible el curso, aparte de los coordinadores.

Ángel Cazorla incidió en lo volátil del mundo en transformación en el que nos hallamos, manifestando la necesidad del análisis y el estudio para paliar las brechas (digital, de género, de clase...) que siguen existiendo y afectan a las prácticas culturales; al cabo, hizo mención de la crecientemente rica "familia atalaya" (sic), a la que espera un gran futuro, recordando a todos que los datos del Observatorio son de libre acceso y animando a su consulta y descarga.

A.J. González Rueda por su parte visibilizaría, mencionándolo, a todo el personal que ha hecho posible el seminario, propio y externo a la UCA; señaló lo complejo y arriesgado del formato, y apuntó en el que se ha tratado de mostrar los equilibrios entre los distintos sectores de la cultura así como las incertidumbres de un momento de cambio 
como el actual, en el que es imprescindible atender a enfoques como el de la desigualdad de género. Concluiría con un apunte a la reflexión de dónde y cómo quedan la crítica y la prescripción, esto es, el aparataje intelectual en el ámbito de la cultura, en este mundo en transición a lo digital. Finalmente agradecería su participación a ponentes y participantes, deseando a todos mucha suerte. 